\title{
Correction to: TRPM7 channel activity in Jurkat T lymphocytes during magnesium depletion and loading: implications for divalent metal entry and cytotoxicity
}

\author{
Alayna Mellott $^{1} \cdot$ Jananie Rockwood $^{1} \cdot$ Tetyana Zhelay $^{1} \cdot$ Charles Tuan Luu $^{1} \cdot$ Taku Kaitsuka $^{2} \cdot$ J. Ashot Kozak $^{1}$ \\ Published online: 2 October 2020 \\ (C) Springer-Verlag GmbH Germany, part of Springer Nature 2020
}

Correction to: Pflügers Archiv - European Journal of Physiology (2020)

https://doi.org/10.1007/s00424-020-02457-3

The original article was published with an error. In Figure $9 \mathrm{~b}$ there are 3 typographical errors: instead of the Greek mu letter it shows the unconverted data. Should be $8 \mathrm{uM}, 20 \mathrm{uM}$ and $400 \mathrm{uM}$. The correct Figure 9 is presented here. The Original article has been corrected.

The online version of the original article can be found at https://doi.org/ $10.1007 / \mathrm{s} 00424-020-02457-3$

J. Ashot Kozak

juliusz.kozak@wright.edu

1 Department of Neuroscience, Cell Biology and Physiology, Boonshoft School of Medicine and College of Science and, Mathematics, Wright State University, Dayton, OH 45435, USA

2 School of Pharmacy in Fukuoka, International University of Health and Welfare, Enokizu 137-1, Okawa, Fukuoka, Japan 
a

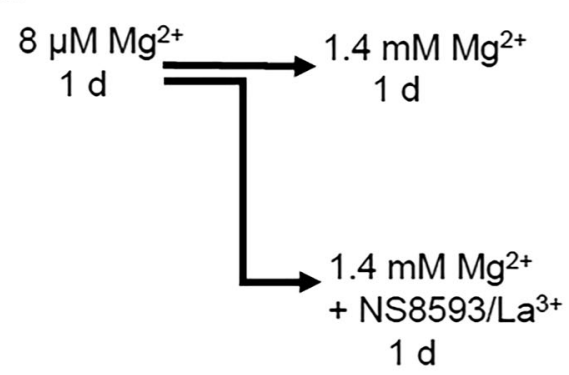

b
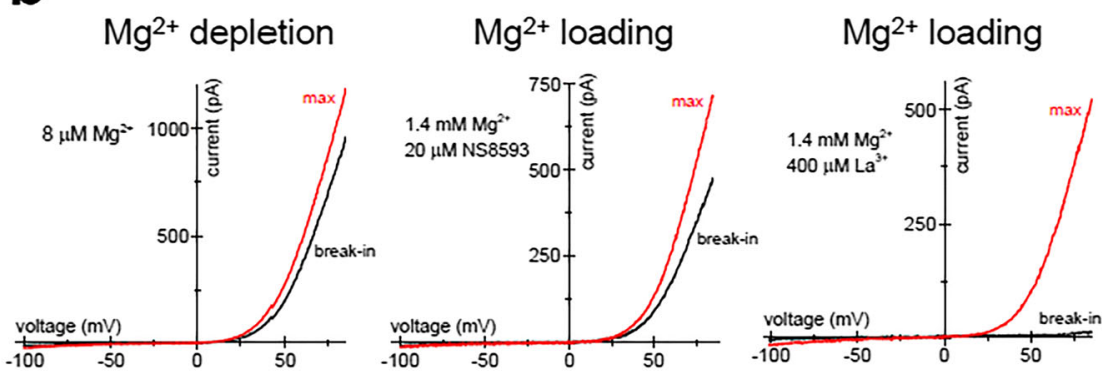

d
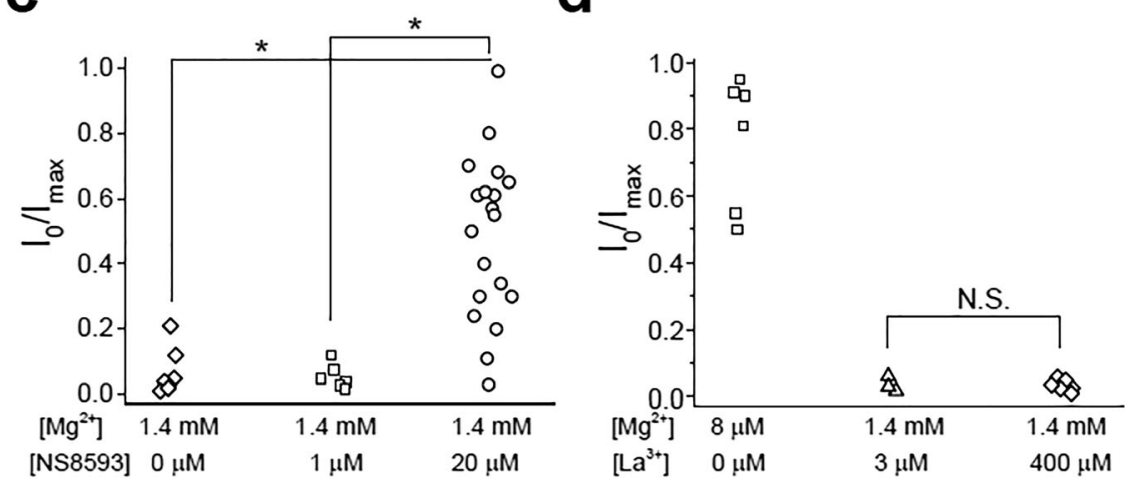

Publisher's note Springer Nature remains neutral with regard to jurisdic-

tional claims in published maps and institutional affiliations. 